\title{
Los problemas son globales, las políticas locales
}

\author{
Antoni Gual \\ Unidad de Alcohología de la Generalitat. \\ Enviar correspondencia a: \\ Unidad de Alcohología de la Generalitat. Servicio de Psiquiatría. Instituto de Neurociencias. Hospital Clínic. IDIBAPS \\ Villarroel, 170. 08036 Barcelona. email: tgual@clinic.ub.es
}

$\mathbf{P}$ robablemente sea cierto que los jóvenes en Almería beben de forma distinta que en Tallin o Tampere, pero no es menos cierto que las diferencias entre unos y otros se han reducido drásticamente en el curso del último decenio. Del mismo modo que en Finlandia o Estonia es fácil encontrar las mismas tiendas de moda que en Andalucia, las formas de vestir, las formas de vivir, las formas de divertirse y las formas de beber también tienden a una progresiva homogeneización a nivel europeo y, probablemente, a nivel mundial. La globalización es un fenómeno que trasciende ámbitos profesionales y afecta decididamente nuestros estilos de vida. Quizas por ello nos resulta familiar el artículo de Nick Heather ${ }^{1}$ sobre el alcohol en el Reino Unido.

La homogeneización de los patrones de consumo es más que evidente. Si el Reino Unido ve con preocupación el ascenso en las tasas de cirrosis alcohólica, en España observamos con asombro como el $35 \%$ de los jóvenes admiten haberse embriagado en el curso del último mes $^{2}$, cifra que casi duplica la de la encuesta escolar del $2002^{3}$, que se situaba en el $19 \%$. ¿El mundo al revés? No. Simplemente globalización. En Inglaterra aumentan las cirrosis y en España se consolida el botellón. El European Report on Alcohol ${ }^{4}$ muestra entre otras cosas datos tan sorprendentes como que los suecos tienden a beber alcohol en las comidas con mayor frecuencia que los españoles y que en cambio el consumo de alcohol sin ingesta alimenticia es hoy en dia mas frecuente en España que en Suecia.

Como es lógico, la homogeneización de patrones de consumo está dando lugar a la progresiva homogeneización de los problemas generados por el consumo de bebidas alcohólicas. No deja de ser significativo el hecho de que en España la alarma social en relación al alcohol haya crecido en los últimos años, cuando curiosamente los niveles globales de consumo se han mantenido estables ${ }^{5}{ }^{6}$. Si admitimos que la accidentabilidad y el botellón son los principales causantes de esa mayor alarma social, deberemos admitir también que la preocupación a menudo es producida por la aparición de problemas a los que nuestra sociedad no estaba habituada, y los consumos masivos de fin de semana son sin duda nuevos para las culturas vitivinícolas?.

Heather manifiesta con razón su preocupación por la evolución de las políticas sobre alcohol en el Reino Unido, y es bueno extender su preocupación a una perspectiva española. Si los nuevos patrones de consumo comportan nuevos problemas, parece obvio que las autoridades deben arrticular nuevas políticas para hacer frente a dichos problemas. En ese sentido, quizás sea bueno recordar ahora lo sucedido con la ley del alcohol que promovió en la anterior legislatura el Plan Nacional sobre Drogas. Se trataba de una ley ambiciosa, que contemplaba el alcohol como droga y promovia medidas relevantes para proteger a la juventud, especialmente en la restricción de la oferta y sobretodo limitando estrictamente la publicidad. Alguien la bautizó como la 'Ley del botellón' y embarrancó. No deja de ser curioso que en el camino se aprobase la 'Ley del vino ${ }^{8}$ que entre otras cosas definió al vino como: 'alimento dentro de la dieta mediterránea' y facilitó su exclusión de la Ley de Prevención del Consumo Indebido de Bebidas Alcohólicas, ley que a nivel estatal ni siquiera llegó a ver la luz.

Es este un buen ejemplo de cómo los poderes públicos afrontan el tema del alcohol: intentando contentar a la opinión pública, y preservando los intereses de los importantes grupos de presión que luchan por preservar y aumentar los espacios que el alcohol ocupa en nuestra sociedad. Si bien es cierto que el alcohol ha generado una cierta alarma social en los últimos años, no es menos cierto que la industria alcoholera ha cambiado sus estrategias, intentando generar un estado de opinión favorable a las bebidas alcohólicas mediante las denominadas "estrategias globales de marketing". En el fondo, si la industria es capaz de ejercer presión directa sobre los gobernan- 
tes, y si mediante sus estrategias globales de marketing es capaz de influir poderosamente en la opinión pública, nuestros gobernantes lo seguirán teniendo muy difícil para promover acciones efectivas que limiten los daños provocados por el consumo de bebidas alcohólicas. En un mundo donde el marketing y el consumo ya se han globalizado, las políticas siguen siendo locales, a pesar de los intentos que la Organización Mundial de la Salud hace para reclamar la creación de marcos legislativos mucho mas amplios ${ }^{9}$. ¿Harán falta muchas cirrosis en Inglaterra y muchos botellones en España para que las políticas se anticipen a los problemas y no vayan siempre detrás de ellos?

El artículo de Nick Heather me hace recordar la Conferencia Ministerial que bajo el título "Alcohol, less is better" 10 organizó en Paris la Organización Mundial de la Salud en 1995. Ya entonces Nick y algunos de sus colegas británicos protestaron enérgicamente frente a la entonces ministra de salud del Reino Unido, por su "brillante" idea de revisar al alza los límites recomendados de consumo alcohólico ${ }^{11}$, contra la opinión de los expertos y del Royal College of Physicians. Dice el refrán que quien siembra vientos recoge tempestades, y aunque lamentablemente nadie podrá ahora pedirle responsabilidades a la ex-ministra, es probable que la elevación de las tasas de cirrosis que padecen los británicos tenga alguna relación con las medidas que la ex-ministra tomó en su dia. Frente a ello, resulta difícil saber si los profesionales, los científicos, aquellos que en definitiva comprobamos en nuestro quehacer cotidiano las secuelas que el alcohol deja en los individuos, en sus familias y en la sociedad, podemos limitarnos a desarrollar nuestro trabajo con neutralidad o deberíamos ser más beligerantes

\section{REFERENCIAS}

1. Heather N. Britain's alcohol problem and what the UK government is (and is not) doing about it. Adicciones, 18, 225-36

2. Ministerio de Sanidad y Consumo. Delegación del Gobierno para el Plan Nacional sobre Drogas. Encuesta domiciliaria sobre abuso de drogas en España 2003.

3. Ministerio de Sanidad y Consumo. 2005. Encuesta estatal sobre uso de drogas en enseñanzas secundarias 2004. http://www.msc.es/pnd/observa/pdf/escolar2004.pdf

4. Anderson, P. and Baumberg, B. (2006). Alcohol in Europe. London: Institute of Alcohol Studies.

5. Gual, A. and Colom, J. 1997. "Why Has Alcohol Consumption Declined in Countries of Southern Europe?" Addiction, 92: S21-S31.

6. Comission for distilled spirits World Drink Trends 2004 Edition. 2004. Biddles Ltd. UK

7. Gual A. Alcohol in Spain. Addiction 2006. In press.

8. LEY 24/2003, de 10 de julio, de la Viña y del Vino. Boletin Oficial del Estado num 165, de 11 de julio del 2003. pp 27.165-27.179. http://www.boe.es/boe/dias/2003/07/11/ pdfs/A27165-27179.pdf accedido el 23/06/2006.

9. Framework for alcohol policy in the WHO European Region. WHO Europe http://www.euro.who.int document/e88335.pdf accedido el 23/06/2006

10. European Charter on Alcohol, European Conference on Health, Society and Alcohol, Paris, France 12-14 December 1995. http://www.euro.who.int/AboutWHO/ Policy/20010927_7 accedido el 23/06/2006.

11. Inter-Departmental Working Group (1995). Sensible Drinking. London: Department of Health. 